\title{
A Quasi-dimensional Numerical Investigation of the Scroll Expander of an Organic Rankine Cycle Unit
}

\author{
Antonio Cantiani ${ }^{1, *}$, Annarita Viggiano $^{1}$, Emanuele Fanelli ${ }^{2}$, and Vinicio Magi ${ }^{1,3}$ \\ ${ }^{1}$ School of Engineering, University of Basilicata, Potenza, 85100, Italy \\ ${ }^{2}$ Technical Unit for Trisaia Technologies (UTTri), ENEA, Rotondella, 75026, Italy \\ ${ }^{3}$ Department of Mechanical Engineering, San Diego State University, CA 92182, USA.
}

\begin{abstract}
Scroll compressors are often used in air conditioning and refrigeration systems thanks to their high efficiency, low noise and vibrations, light weight and high reliability. Scrolls are also widely used as positive displacement expanders in small-scale power generation systems, such as Organic Rankine Cycles (ORCs). In recent years, the research has focused on the development of mathematical models that help to predict the scroll expander performances under different operating conditions. In this work, a quasi-dimensional model of a scroll expander of an Organic Rankine Cycle unit is presented. Such an expander consists of two identical circle involute spirals, with appropriate starting segments. Specifically, the model is able to design the scroll expander geometry with either a "circular cutter" or a "perfect mesh profile" (PMP) approach, which are two of the most common scroll geometry starting segments. As regards the thermo-fluid dynamic aspects, specific sub-models have been used to account for radial and axial leakage, wall heat transfer, intake and exhaust of the working fluid. The model has been validated with available experimental data in order to assess its accuracy and, at the same time, to calibrate the implemented sub-models. The influence of some geometrical parameters on the expander performances has been assessed. In particular, a study of the influence of the wrap geometry is presented. The results show that the circular cutter approach returns better performances at the expenses of a higher mass consumption. Nevertheless, the circular cutter modification returns a higher specific work. Lastly, the influence of one of the PMP parameters on performances has been assessed. The results show a fairly strong dependence of both mechanical power and specific work, suggesting that the global optimization of all geometric parameters of the scroll expander may radically improve its performances.
\end{abstract}

\section{Introduction}

Current efforts on limiting environmental impact of human activities result in an increased attention towards renewable energy sources and energy efficiency. In particular, a

\footnotetext{
*Corresponding author: antonio.cantiani@unibas.it
} 
relatively large amount of energy can be recovered from waste heat of internal combustion engines, gas turbines and various industrial processes, such as cement steel, glass production, oil and gas sector [1-4], etc. For low-enthalpy energy recovery, Organic Rankine Cycles (ORCs) are commonly used since they provide better performances when compared with other available technologies, such as Stirling engines, thermo-electric generators, and inverted Brayton cycles [5]. Campana et al. [1] estimated that up to $20 \mathrm{TWh}$ per year of thermal energy could be recovered by means of Organic Rankine Cycles from a relatively few industrial plants selected in Europe, leading to a 7.6 Mton reduction in terms of $\mathrm{CO} 2$ emissions.

One of the ORCs key components is the expander, since it provides the energy actually converted into useful work. For ORCs output mechanical power above $50 \mathrm{~kW}$, radial inflow turbines give the best performances, whereas, for small and micro ORC units, volumetric expanders are preferred [6-8]. Among volumetric expanders, scroll expanders are widely used in such units, thanks to their high efficiency, simple manufacturing, lightweight, low noise and low vibrations [8-9]. In recent years, the research has focused on the development of mathematical models that help to predict the scroll expander performances under different operating conditions. Ma et al. [10] developed a scroll expander model that takes into account the friction between stator and rotor during their relative motion. With such a model, it is possible to determine the expander rotating speed and mass flow rate for specific load conditions. Yang et al. [11] have used a quasidimensional model to compare the performances of a scroll expander operating with different working fluids. In particular, their work focuses on the performances obtained by employing R1233zd(e) fluid, which may replace the common working fluid R245fa. The results have shown a similar behaviour for the two working fluids, with a slightly better isentropic efficiency obtained with R245fa. Hence, R1233zd(e) can be considered as a valid alternative working fluid. Zhang et al. [12] have studied the effects of specific operating conditions (inlet pressure and temperature) and geometric parameters (clearance and vanes height to pitch ratio) on the expander performances. The study found that, for a given speed, the volumetric efficiency is the same, whereas scroll expander mass flow rate and power output increase with the inlet pressure. The vanes to height pitch ratio also has a great impact on the expander performances.

In this work, a quasi-dimensional model of a scroll expander of an Organic Rankine Cycle (ORC) unit is presented. The model provides details on how to design the scroll expander geometry, which consists of two identical circle involutes with appropriate starting segments. Specifically, the starting segments can either follow a "circular cutter" approach or a "perfect mesh profile" (PMP) approach, which are two of the most common approaches for designing the scroll geometry starting segments [10]. The influence of the geometrical parameters on the expander performances is clearly assessed. The model has been validated against experimental data available in the literature, returning a good agreement both in terms of power and mass flow rate at different rotating speeds. This work is organized as follows: first the scroll expander geometry is described, along with two interesting modifications of the starting segments, then the mathematical and numerical models are given, the results are discussed and, finally, the conclusions are summarized.

\section{The Scroll expander geometry}

In this work, the geometry of the scroll expander consists of two identical circle involute profiles for both stator and rotor. A schematic representation of the expander is shown in Fig. 1. Since the scroll wraps walls have a thickness s, the circle involute parametric equations need to be modified in order to describe an inner involute profile and 
an outer involute profile. Eqs. (1) represent the inner $(-\alpha)$ and outer $(+\alpha)$ involute parametric equations, where $\varphi$ is the involute angle and a is the involute basic circle radius:

$$
x=a[\cos \varphi+(\varphi \pm \alpha) \sin \varphi], \quad y=a[\sin \varphi-(\varphi \pm \alpha) \cos \varphi]
$$

The thickness is given by:

$$
s=2 a \alpha
$$

The involute starts at $\varphi=0$ and ends at $\varphi=(2 \mathrm{~ns}+1 / 2) \pi$, where $n s$ is the number of chamber pairs. In order to have a functioning scroll expander, the rotor must be rotated by $\pi$ respect to the stator. This can be achieved by simply changing sign to Eqs. (1).

The rotor trajectory radius can be determined by Eq. (3), where $\mathrm{cr}$ is the radial clearance between stator and rotor at each point:

$$
r_{t r j}=\pi a-2 a \alpha-c_{r}
$$

Hence, the rotor position at any orbiting angle $\theta$ can be determined by:

$$
x_{0 r}=r_{t r j} \cos \theta, \quad y_{0 r}=r_{t r j} \sin \theta .
$$

In order to get properly operating conditions, the involute profile of the scroll wraps needs a modified starting segment. The two modifications implemented in the model are presented in the following section. A detailed derivation of the equations can be found in [10].

\section{प.1 Starting segments}

\subsubsection{Circular cutter}

As shown in Fig. 1a, where the stator and the rotor consist of circle involutes, an interference between the wraps tip will result during the rotor orbiting motion. One option to avoid such an interference is to cut the first part of both involutes profile by means of a circular cutter. The circular cutter must be centered on the intersection between the left side of the involute basic circle and the $\mathrm{x}$-axis to design the stator starting segment, whereas it must be centered on the intersection of the right side of the involute basic circle and the $\mathrm{x}$ axis to design the rotor starting segment. The circular cutter radius is given by:

$$
r_{c c}=a(\pi-\alpha)
$$

The resulting profile is shown in Fig. $1 \mathrm{~b}$. The starting orbiting angle $\theta_{\text {start }}$ provides the expander starting position, which is defined as the position of the rotor that disconnects a new chamber. This angle is computed from Eq. (6) and Eq. (7):

$$
\theta_{\text {start }}=\varphi_{p}+\frac{\pi}{2}
$$




$$
\left(\varphi_{p}+\alpha\right)^{2}+2 \cos \varphi_{p}+2\left(\varphi_{p}+\alpha\right) \sin \varphi_{p}=(\pi-\alpha)^{2}-2
$$
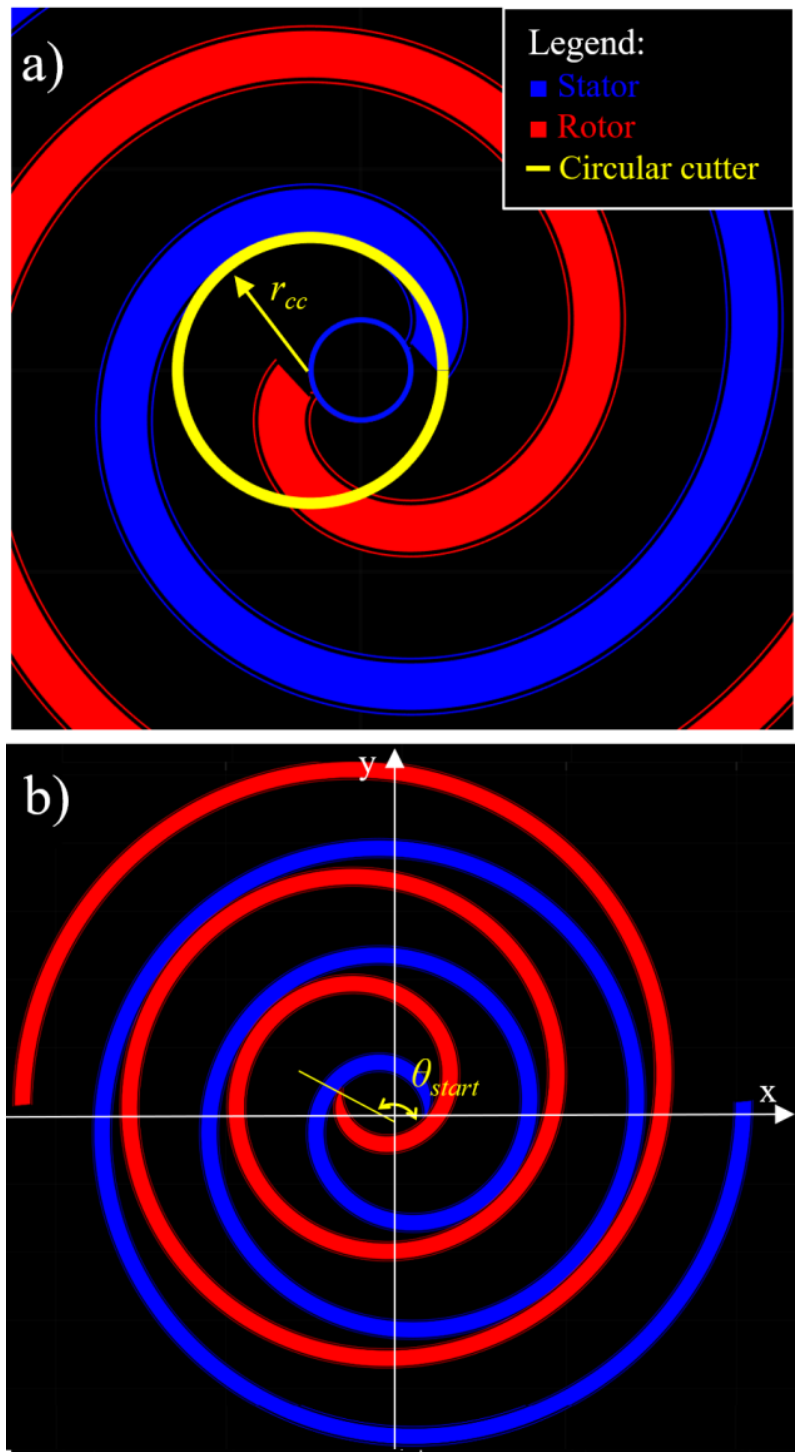

Fig. 1. (a) Circular cutter position and radius for stator modification and (b) final geometry at the starting orbiting angle.

It should be pointed out that, with the circular cutter geometry modification, the first chamber does not start with zero volume, but with a given initial volume.

\subsubsection{Perfect mesh profile (PMP)}

The PMP approach is more complex with respect to the circular cutter approach, from both manufacturing and geometrical points of view. Specifically, from the manufacturing point of view, an ad-hoc tool path is required, while the circular cutter modification just needs a cutter with a specified diameter. However, the resulting profile has no sharp edges 
and the first chamber volume starts from zero and continuously increases. From the geometrical point of view, the first portion of the circle involute is replaced by two circles with different radius, as showed in Fig. $2 \mathrm{a}$. The angle $\varphi_{a}$ is given as an input parameter. Then, the angle $\beta, \lambda$ and $\gamma$ can be determined by Eqs. (8):

$$
\cot \beta=\varphi_{a}+\frac{\pi}{2}, \quad \lambda=\pi-2 \beta, \quad \gamma=\frac{\pi}{2}-\lambda
$$

The radius of the two circles are given by:

$$
R_{1}=a\left(\frac{1}{\sin \lambda}+\alpha-\frac{\pi}{2}\right), \quad R_{2}=a\left(\frac{1}{\sin \lambda}-\alpha+\frac{\pi}{2}\right)
$$

The angle $\gamma$ is the starting orbiting angle $\theta_{\text {start }}$ (Fig. 2b)
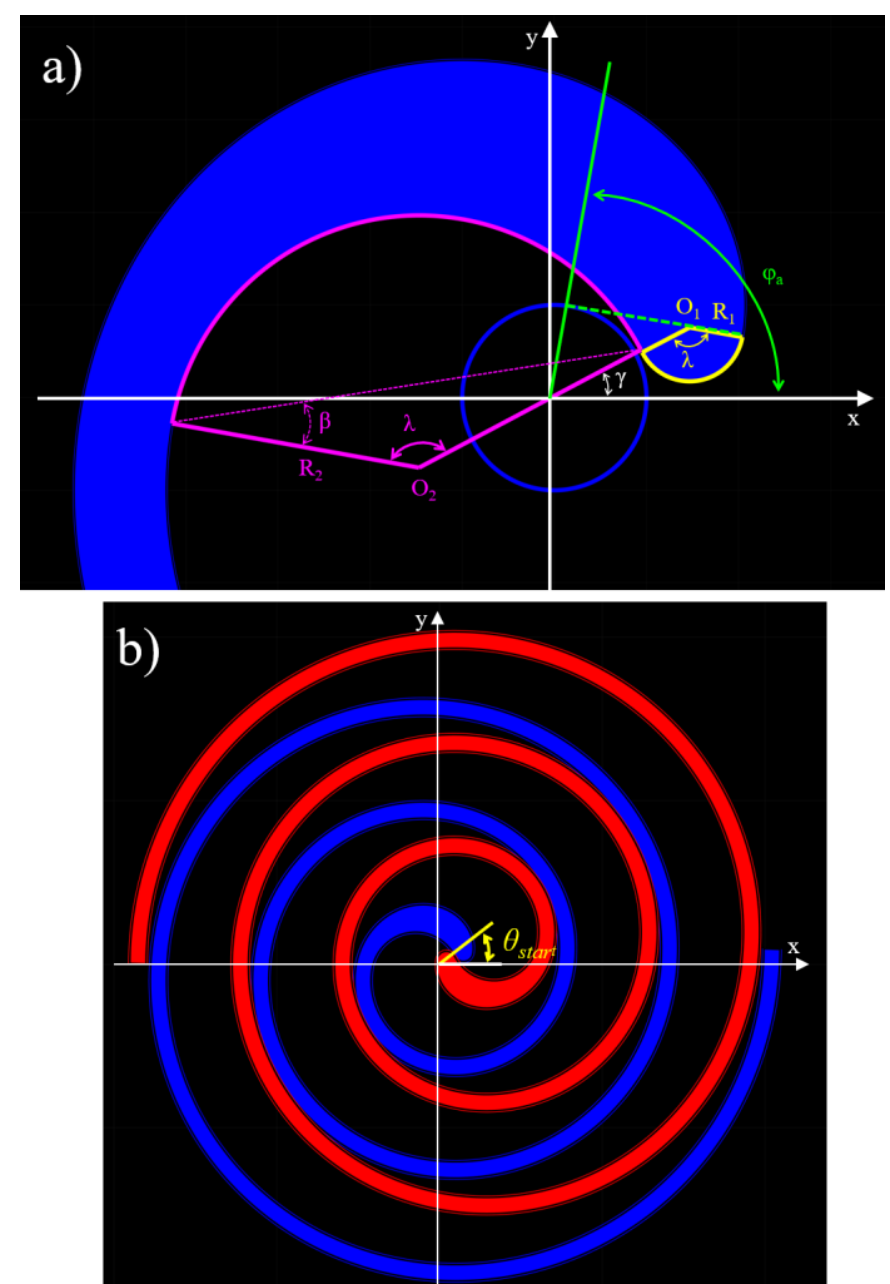

Fig. 2. Stator with PMP modification: geometry details (a) and final geometry (b). 


\subsection{Chambers geometry}

Both geometry modifications result in two sets of symmetrical chambers. Therefore, only one set of chambers is taken into account for the evaluation of the chamber volumes. Fig. 3a shows one set of chambers of a scroll expander based on the circular cutter approach. In order to make the computations suitable for both scroll geometries, the chamber volume is evaluated by means of an analytical equation when this chamber is fully bounded within circle involute segments (yellow bounded chambers of Fig. 3a). This chamber volume is determined by Eq. (10):

$$
V=2 \pi a^{2}(\pi-2 \alpha)(\theta-3 \pi+2 \pi j) z
$$

This equation comes from the circle involute integral between the meshing points of the chamber $j$ at the orbiting angle $\theta$. In the equation, $z$ is the expander height. This equation is applied from chamber 2 to chamber $n-2$, where $n$ is the number of chambers. The volume of chamber n-1 is obtained from Eq. (10) with $\theta_{\text {start }} \leq \theta \leq 2 \pi$, since at $\theta=2 \pi$ the discharge port starts to open and the chamber volume is determined as the last chamber, which is described later.

As starting segments create the first chamber, i.e. magenta bounded chamber of Fig. 3a, its volume is numerically determined by using the trapezium rule with an involute angle step $\Delta \varphi$ ten times lower than the orbiting angle step $\Delta \theta$, in order to avoid numerical instabilities along the chamber volume computation.

As regards the last chamber volume, i.e. green bounded chamber of Fig. 3a, as well as the n-1 chamber for $\theta>2 \pi$, its evaluation must take into account the discharge port opening. The outlet section is assumed to be horizontal to the rotor tip, as shown in Fig. 3b. The involute angle $\varphi$ of the point $\mathrm{P}$ of Fig. $3 \mathrm{~b}$ is unknown. This angle is obtained by Eq. (1) by means of a Newton-Raphson method, giving as an input the y coordinate of the rotor tip. Then, the chamber volume is evaluated by employing the trapezium rule. The outlet section area is computed by multiplying the distance between the two points at the outlet by the expander height $z$. The chambers volume calculation for the PMP approach follows the same process, therefore it is not given here. The outlet area vs crank angle is shown in Fig. $5 \mathrm{~b}$ and Fig. $6 \mathrm{~b}$ for the two geometries, respectively.

Figure 4 shows the chamber volume vs crank angle for circular cutter (Fig. 4a) and PMP (Fig. 4b) approaches when the number of chamber pairs is equal to 3 (Fig. 3a). It is noticed that the circular cutter approach gives a non-zero initial volume, as opposed to the PMP approach. Moreover, the circular cutter approach returns a larger first chamber final volume at $360 \mathrm{CAD}$ with respect to that based on PMP approach. After one complete rotor rotation, i.e. $360 \mathrm{CAD}$, the first chamber splits into three chambers with the circular cutter approach and into two chambers for the PMP approach, which is represented by the discontinuities of Figs. $4 \mathrm{a}$ and $4 \mathrm{~b}$, respectively. 

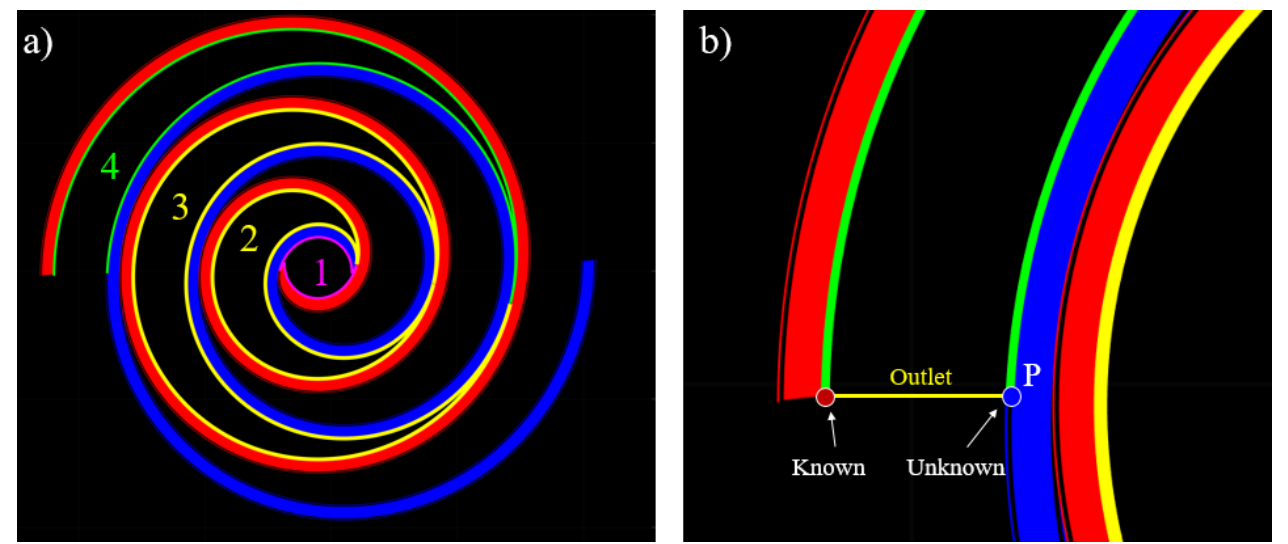

Fig. 3. Scroll expander with circular cutter modification (stator in blue, rotor in red). One set of chamber is highlighted (a) and a detailed view of the discharge port is shown (b).

a)

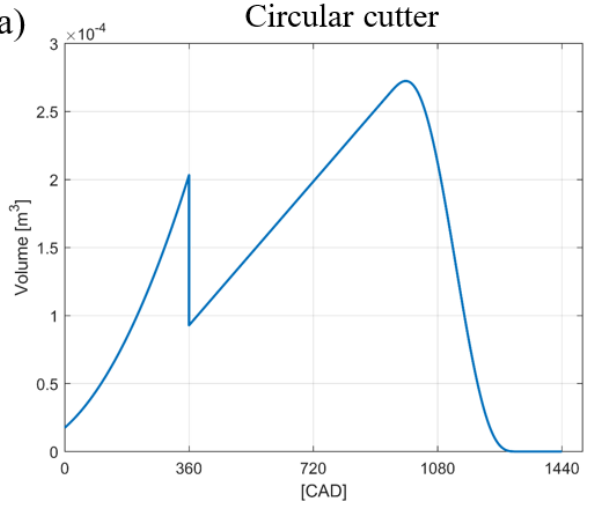

b)

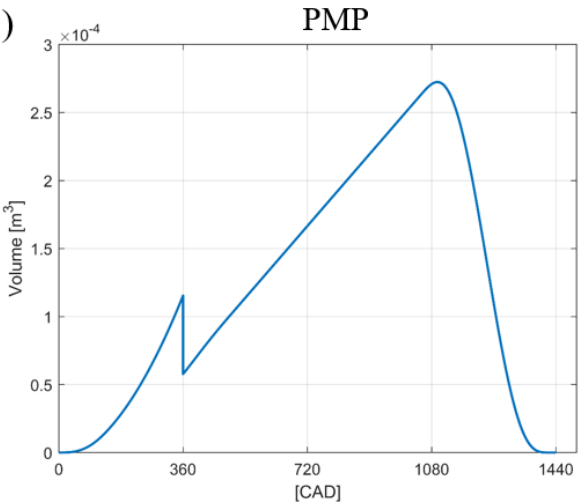

Fig. 4. Chamber volume vs crank angle for the circular cutter (a) and PMP (b) geometries.

\subsection{Inlet port}

One of the main advantages of scroll expanders is the avoidance of moving parts, such as intake or exhaust valves. The intake consists of an inlet port on the stator base plate. During the rotor orbiting motion, the inlet port is fully opened, partially opened or fully closed. In case of partially opening, a reduction of the inlet mass flow rate and an increase of in-chamber pressure drop occur. Therefore, the influence of the inlet port shape and position on the scroll expander performances needs to be carefully addressed. In this work, the inlet port is assumed to be circular and its overlapping area with the chambers is computed at each time-step.

Figure 5a shows a rotor position where the inlet port is partially covered by the rotor (circular cutter approach). The covered (by the rotor) inlet area is numerically determined as the integral of the closed loop A-B-C, by using the trapezium rule. Figure $5 \mathrm{~b}$ shows the inlet port area vs the rotor angle. It is noted that after one complete rotation, the inlet port area is equal to zero since there is not overlapping between the chamber and inlet port. Since the circular cutter approach returns a non-zero starting volume for the first chamber, the inlet port can be located such that the minimum overlapping area is zero, i.e. fully enclosed. Based on this configuration, each chambers pair have the same thermodynamic properties, thus the computations can be limited to only one chamber set, which results in a lower computational time. On the other hand, with the PMP approach, the initial volume of 
the first chamber is zero and a fraction of the inlet port area may overlap with only one of the two new starting chambers. This leads to different thermodynamic conditions for the two sets of chambers, and the computations are performed for both chambers sets. Figure 6a shows a configuration where the inlet port discharges fresh gas into both the first and the second chamber, and Fig. 6b shows the inlet port area vs crank angle. It should be noticed that the inlet area is non-zero even after one complete rotation, since a fraction of the intake port overlaps the second chamber.
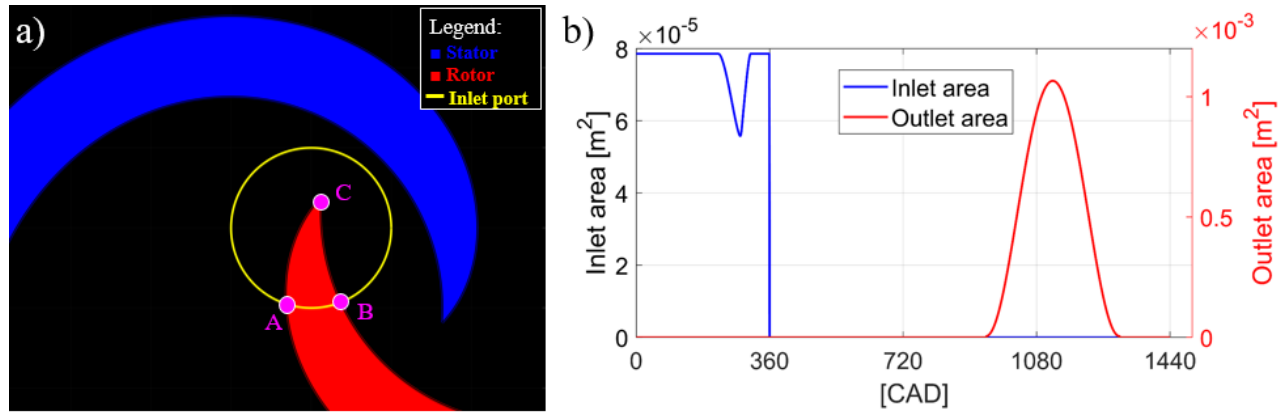

Fig. 5. Influence of the rotor motion on the intake port area (circular cutter geometry approach): intake port partially covered by the rotor (a) and inlet and outlet area vs CAD (b).
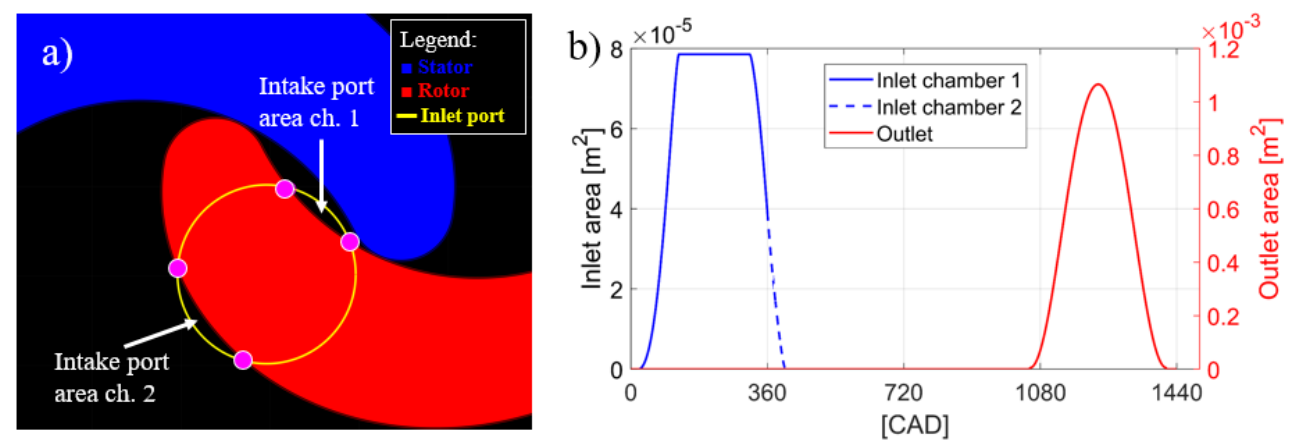

Fig. 6. Influence of the rotor motion on the intake port area (PMP geometry approach): intake port covered by the rotor (a) and inlet and outlet area vs CAD (b).

\subsection{Side walls}

Side walls surface needs to be evaluated due to wall heat transfer and axial tolerance leakages. Such surface consists of the length of the scroll wrap segment multiplied by the expander height $\mathrm{z}$. In this work, for both geometries, the scroll wrap can be formed by a circle arc and/or a circle involute arc. The circle involute arc length 1 is given by:

$$
l=a\left\lfloor\frac{1}{2}\left(\varphi_{2}^{2}-\varphi_{1}^{2}\right) \pm \alpha\left(\varphi_{2}-\varphi_{1}\right)\right\rfloor
$$

where $\varphi_{1}$ and $\varphi_{2}$ represent the initial and final involute angles of the involute segment, respectively, with $+\alpha$ for the outer involute and $-\alpha$ for the inner involute. 


\section{THE QUASI-DIMENSIONAL MODEL}

A quasi-dimensional model has been developed to analyze the performance of the expander. The model solves a system of ODE's which consists of the mass conservation equation, Eq. (12), and the energy conservation equation, Eq. (13), for each chamber:

$$
\begin{gathered}
\frac{d m}{d t}=\frac{d m_{\text {inlet }}}{d t}+\frac{d m_{r l}}{d t}+\frac{d m_{a l}}{d t}+\frac{d m_{\text {outlet }}}{d t}, \\
\frac{d E}{d t}=\frac{d m_{\text {inlet }}}{d t} H_{\text {inlet }}+\frac{d m_{r l}}{d t} H_{r l}+\frac{d m_{a l}}{d t} H_{a l}+\frac{d m_{\text {outlet }}}{d t} H_{\text {outlet }}-p d V+\frac{d Q_{w}}{d t} .
\end{gathered}
$$

In Eq. (12), $\mathrm{m}$ is the chamber mass, $\mathrm{m}_{\text {inlet }}$ is the inlet mass flow rate, $\mathrm{m}_{\mathrm{rl}}$ is the radial leaks mass flow rate, mal is the axial leaks mass flow rate, $m_{\text {outlet }}$ is the outlet mass flow rate. In Eq. (13), $\mathrm{E}$ is the total internal energy, $\mathrm{H}_{\text {inlet }}$ is the inlet flow mass specific enthalpy, $\mathrm{H}_{\mathrm{rl}}$ is the radial leaks flow mass specific enthalpy, Hal is the axial leaks flow mass specific enthalpy, $\mathrm{H}_{\text {outlet }}$ is the outlet flow mass specific enthalpy, $\mathrm{p}$ is the chamber pressure, $\mathrm{V}$ is the chamber volume and $\mathrm{Q}_{\mathrm{w}}$ is the chamber heat transfer.

The working fluid thermodynamic properties are evaluated by using the CoolProp libraries [14]. The use of the CoolProp libraries allows an accurate determination of all the thermodynamic properties for any specific thermodynamic condition. In addition, the computations can be easily performed with a large variety of working fluids.

The radial leakage and axial leakage mass flow rates are determined considering the thermodynamic state of the fluid in the two chambers involved. The mass flow model accounts for backflow and limits the mass flow rate to choking conditions. Both the intake and discharge processes consider the instantaneous intake/exhaust port area and pressure ratio to determine the respective mass flow rates. In particular, the intake port model considers at each time-step the actual position of the rotor, which may partially cover the intake port.

As regards the heat transfer model, it has been assumed that the wall temperature distribution does not change with time, regardless of the heat flux. This means that the stator and rotor heat capacity is considerably higher than the working fluid heat capacity. The experimental measurements of Jang et al. [15] found that the temperature profile along a scroll wrap is almost linear with respect to the involute angle. Based on their results, the scroll wrap temperature Tw has been determined according to:

$$
T_{w}=\left(T_{\text {in }}-10\right)-\frac{T_{\text {in }}-T_{\text {out }}-20}{\varphi_{\text {end }}} \varphi,
$$

where $T_{\text {in }}$ is the working fluid inlet temperature, $T_{\text {out }}$ is the outlet fluid temperature, pend is the wrap last point angle.

As regards the convective heat transfer coefficient $\mathrm{h}$, the empirical correlation proposed by Jang et al. [15] has been used. This correlation has been specifically developed to determine the heat transfer in a scroll compressor and it takes into account the total chamber mass flow, the rotor speed and the scroll geometry.

For a given chamber, the heat transfer $\mathrm{Q}_{\mathrm{w}}$ is determined by: 


$$
Q_{w}=h\left\lfloor A_{s}\left(T_{w s}-T\right)+A_{r}\left(T_{w r}-T\right)+A_{p}\left(T_{p}-T\right)\right\rfloor,
$$

where $T$ is the in-chamber fluid temperature, $A_{s}$ is the stator side wall area, $T_{w s}$ is the stator side wall average temperature. The variables with subscript $r$ refer to the rotor side wall, while subscript $p$ refers to top and bottom walls. In particular, the top and bottom wall temperature $T_{p}$ is computed as the area-weighted average temperature of the stator and rotor side wall.

The system of ODE represented by Eq. (12) and Eq. (13) is time integrated with a firstorder accurate Euler method. A time step of $0.001 \mathrm{CAD}$ (which corresponds to $1.67 \mathrm{e}-7 \mathrm{~s}$ at $1000 \mathrm{rpm}$ ) has been selected. The initial fluid thermodynamic conditions are set to the value of the inlet fluid temperature and pressure. For all cases, six complete rotations ensure to reach of cyclic convergence.

\section{RESULTS}

\subsection{Model validation}

The present numerical model has been validated by comparing the results in terms of mechanical power output and average intake mass flow rate with experimental data available in the literature [16]. The expander specifications are listed in Table 1. Figure 7a compares the experimental measurements with the numerical results. The figure shows a very good matching between numerical and experimental results with an almost linear increase of mass flow rate and mechanical power with rpm. Figure $7 \mathrm{~b}$ highlights the influence of the intake port partially overlapped by the rotor on the chamber pressure for different rotating speeds. The figure shows that this influence is higher as the rotating speed increases, suggesting that the inlet port location has a greater impact on performances as the scroll expander speed increases.

Table 1. Scroll expander specifications

\begin{tabular}{lc}
\hline \multicolumn{1}{c}{ Geometry parameters } \\
\hline $\mathrm{a}$ & $3.66 \mathrm{~mm}$ \\
$\mathrm{~s}$ & $4.6 \mathrm{~mm}$ \\
Number of chamber pairs & 3 \\
Chamber height & $40 \mathrm{~mm}$ \\
Radial clearance & $0.015 \mathrm{~mm}$ \\
Axial clearance & $0.04 \mathrm{~mm}$ \\
Inlet radius & $6.5 \mathrm{~mm}$ \\
Inlet center position $(\mathrm{x}, \mathrm{y})$ & $(-2.17 \mathrm{~mm}, 2.17 \mathrm{~mm})$ \\
& \\
\hline Thermodynamic parameters & \\
\hline Fluid & air \\
Inlet pressure & $3.4 \mathrm{bar}$ \\
Inlet temperature & $292.15 \mathrm{~K}$ \\
Outlet pressure & $1.013 \mathrm{bar}$ \\
Outlet temperature & $288.2 \mathrm{~K}$ \\
\hline
\end{tabular}



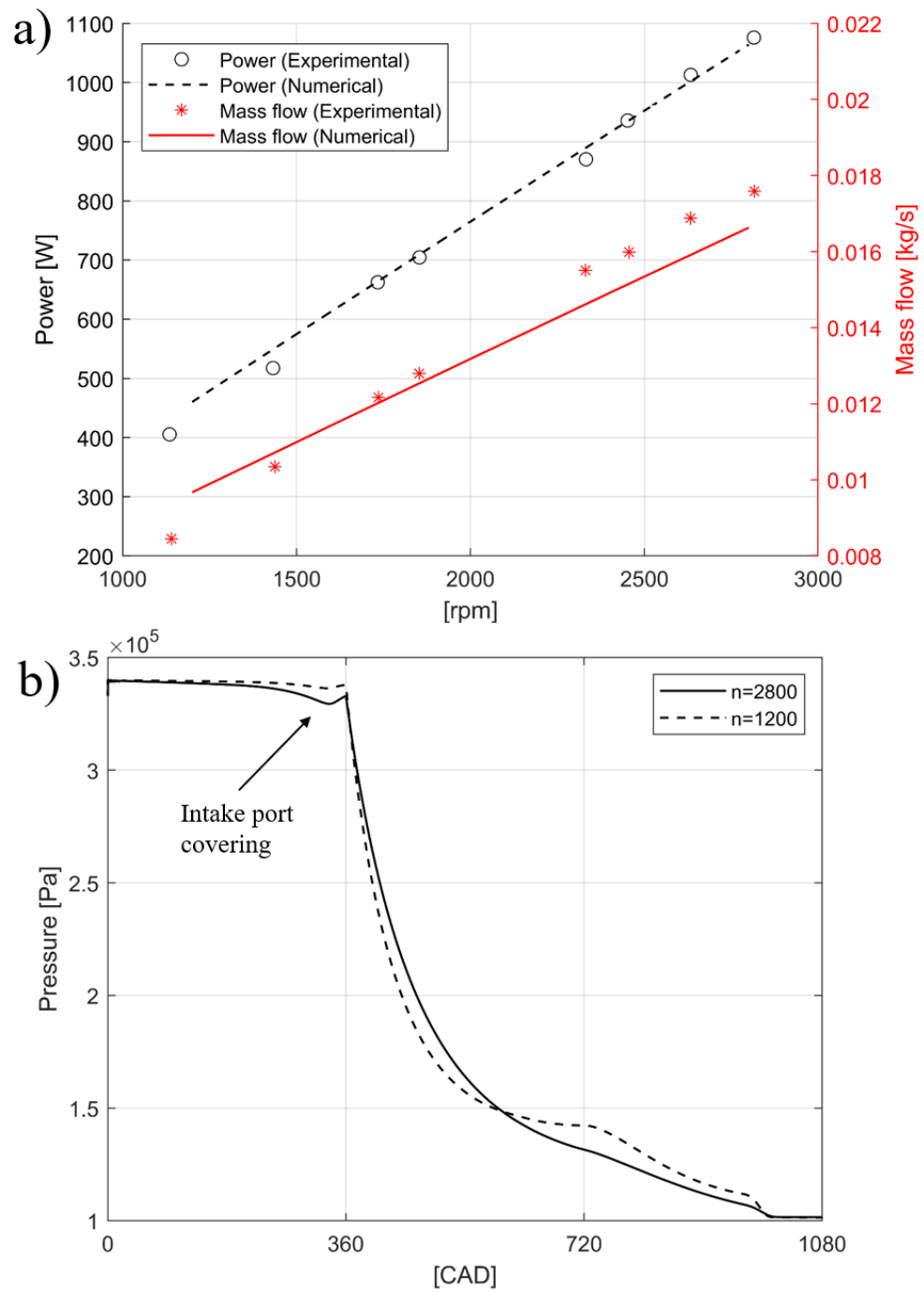

Fig. 7. Experimental measurements [16] vs numerical results at different rotating speeds (a) and effect of the intake port overlapping on chamber pressure at different speeds (b).

\subsection{Influence of the scroll geometry}

In order to analyze the influence of the scroll geometry on its performances, the model has been employed to simulate a scroll expander with the geometry specified in Table 1 and starting segments obtained with both circular cutter and PMP approaches, setting $\varphi_{\mathrm{a}}=90^{\circ}$. Figure 8a compares the output mechanical power obtained from the scroll expander and the average mass flow rate as a function of the rotor speed for the two geometries. The figure shows that a higher power and mass flow rate are obtained for the circular cutter geometry with respect to the PMP. In order to compare the efficiency of the two geometries, the specific work obtained from the expander should be computed. Figure $8 \mathrm{~b}$ compares the specific work of the two geometries, calculated as the ratio between the power output and the mass flow rate at a given rotating speed. The PMP geometry shows a slightly better energy conversion performance at low rotating speeds (below $1500 \mathrm{rpm}$ ), while the circular 
cutter geometry performs better at higher rotating speeds. It should be pointed out that the simulation for the PMP modification has been performed with the same geometry parameters of the circular cutter modification. In particular, the inlet port position and shape may play a significant role on the performances of an expander with PMP geometry, since it determines the inlet mass flow that discharges directly into the second chamber. An appropriate optimization process could improve the performances of an expander with such a modification. In addition, some considerations on the effect of the $\varphi_{a}$ angle on the scroll expander with PMP geometry performances have been addressed. This parameter affects the expander performances, not only in terms of output power and mass flow rate (Fig. 9a) but also in terms of specific work (Fig. 9b). A global optimization of all geometric parameters, including the inlet port shape and location, may significantly improve the expander performances for both geometries.
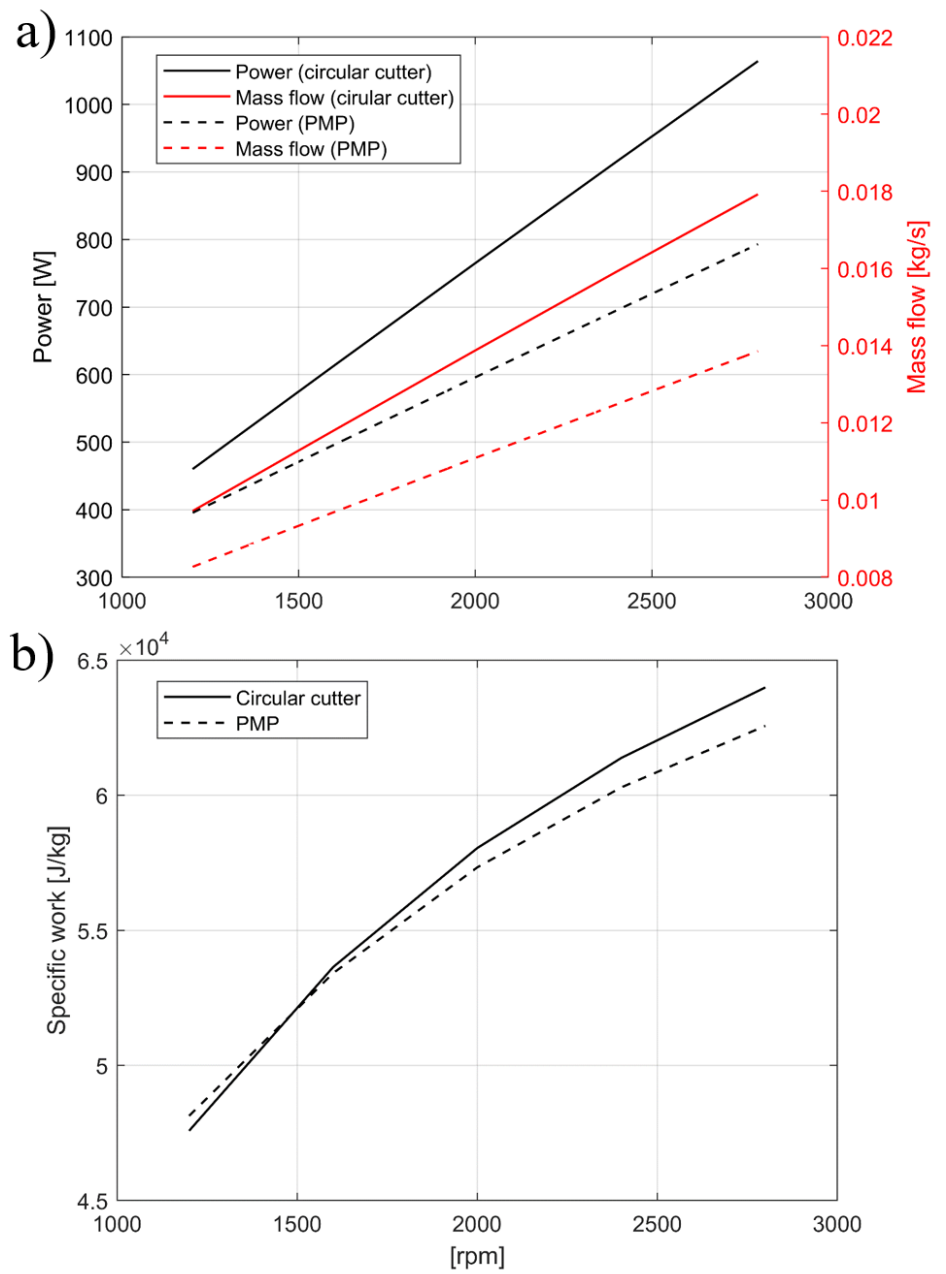

Fig. 8. Circular cutter vs PMP geometry comparison: power and mass flow vs rotating speed (a) and specific work vs rotating speed (b). 
a)

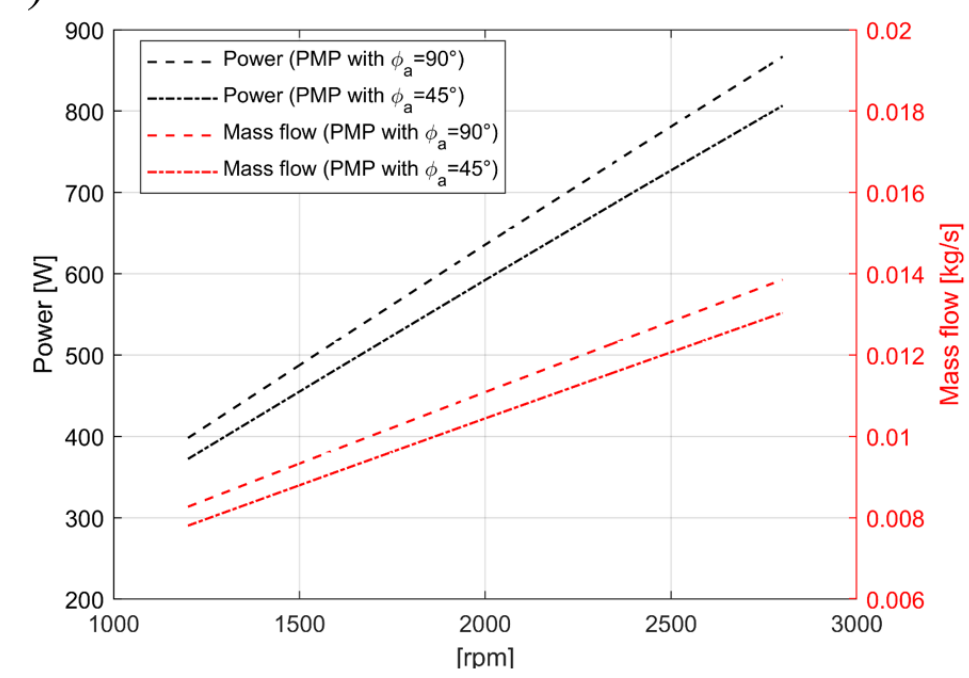

b)

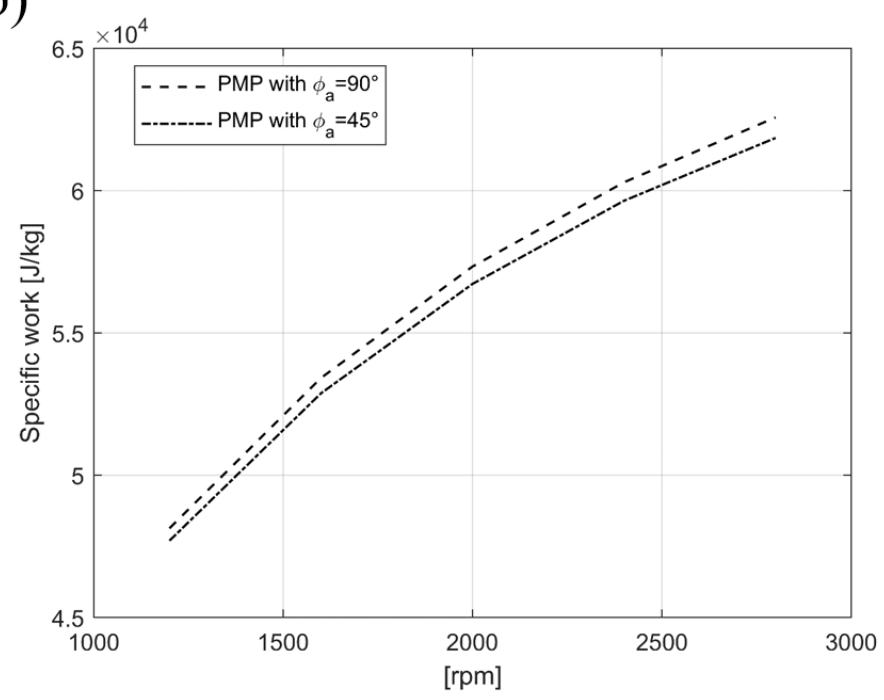

Fig. 9. Effect of the $\varphi_{a}$ angle on expander performances: power and mass flow vs rotating speed (a) and specific work vs rotating speed (b).

\section{CONCLUSIONS}

In this work, a detailed quasi-dimensional model of a scroll expander is presented. The model accounts for both radial and axial tolerance mass leakage, heat transfer and the partial intake port covering that occurs during the rotor orbiting motion. The model can perform calculations of the scroll expander performances with two of the most common starting segment modifications, which are the "circular cutter" and "perfect mesh profile" modifications. The model has been validated against experimental data available in the literature, returning a good agreement both in terms of power and mass flow rate at different rotating speeds. The performances of expanders with the same geometrical parameters but different starting segment modification have been compared. The results 
show that the circular cutter modification offers a higher power output together with a higher mass flow rate, at any of the rotating speeds tested. In terms of specific work, the PMP modification performs better than the circular cutter modification only at low rotating speed $(<1500 \mathrm{rpm})$. It should be pointed out that the geometry with PMP modification has the same geometric parameters than the circular cutter modification, which may compromise its performances. In particular, the intake port position and shape play a significant role in the expander performances, and its optimization could considerably improve them. In addition, the effect of the $\varphi_{\mathrm{a}}$ angle on performances has been assessed. The results show that higher performances correspond to larger values of $\varphi_{\mathrm{a}}$, which further indicates that the optimization of the scroll expander geometric parameters may significantly improve the expander performances.

\section{References}

1. F. Campana, M. Bianchi, L. Branchini, A. De Pascale, A. Peretto, M. Baresi, A. Fermi, N. Rossetti, R. Vescovo. "ORC waste heat recovery in European energy intensive industries: Energy and GHG savings." Energy Conversion and Management 76, (2013): 244-252, doi: 10.1016/j.enconman.2013.07.041

2. A. Mahmoudi, M. Fazli, M. R. Morad. "A recent review of waste heat recovery by Organic Rankine Cycle." Applied Thermal Engineering 143 (2018): 660-675, doi: 10.1016/j.applthermaleng.2018.07.136

3. A. Auld, A. Berson, S. Hogg. "Organic Rankine cycles in waste heat recovery: a comparative study." International journal of low-carbon technologies 8 .suppl_1 (2013): i9-i18, doi: 10.1093/ijlct/ctt033

4. Z. Varga, I. Rabi, C. Farkas. "Waste heat recovery with organic Rankine cycle in the petroleum industry." Chem Eng 29 (2012), doi: 10.3303/CET1229051

5. M. Bianchi, A. De Pascale. "Bottoming cycles for electric energy generation: parametric investigation of available and innovative solutions for the exploitation of low and medium temperature heat sources." Applied Energy 88.5 (2011): 1500-1509, doi: $\underline{10.1016 / \text { j.apenergy.2010.11.013 }}$

6. F. Alshammari, M. Usman, A. Pesyridis. "Expanders for Organic Rankine Cycle Technology." Organic Rankine Cycle Technology for Heat Recovery (2018): 41, doi: $\underline{10.5772 / \text { intechopen. } 78720}$

7. S. Emhardt, G. Tian, J. Chew. "A review of scroll expander geometries and their performance." Applied Thermal Engineering 141 (2018): 1020-1034, doi: 10.1016/j.applthermaleng.2018.06.045

8. J. Bao, L. Zhao. "A review of working fluid and expander selections for organic Rankine cycle." Renewable and sustainable energy reviews 24 (2013): 325-342, doi: 10.1016/j.rser.2013.03.040

9. Z. Jiang, D. K. Harrison, K. Cheng. "Computer-aided design and manufacturing of scroll compressors." Journal of Materials Processing Technology 138.1-3 (2003): 145151, doi: 10.1016/S0924-0136(03)00063-3

10. Z. Ma, H. Bao, A. P. Roskilly. "Dynamic modelling and experimental validation of scroll expander for small scale power generation system." Applied energy 186 (2017): 262-281, doi: 10.1016/j.apenergy.2016.08.025

11. J. Yang, Z. Sun, B. Yu, J. Chen, "Modeling and optimization criteria of scroll expander integrated into organic Rankine cycle for comparison of R1233zd (E) as an alternative to R245fa." Applied Thermal Engineering 141 (2018): 386-393, doi: 10.1016/j.applthermaleng.2018.06.001

12. X. Zhang, Y. Xu, J. Xu, Y. Sheng, Z. Zuo, J. Liu, H. Chen, Y. Wang, Y. Huang, "Study on the performance and optimization of a scroll expander driven by 
compressed air." Applied Energy 186 (2017): 347-358, doi: 10.1016/j.apenergy.2016.06.004

13. K. Jang, S. Jeong. "Experimental investigation on convective heat transfer mechanism in a scroll compressor." International Journal of Refrigeration 29.5 (2006): 744-753, doi: 10.1016/j.ijrefrig.2005.12.002

14. I. H. Bell, J. Wronski, S. Quoilin, V. Lemort, "Pure and pseudo-pure fluid thermophysical property evaluation and the open-source thermophysical property library CoolProp." Industrial \& engineering chemistry research 53.6 (2014): 2498-

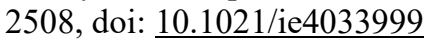

15. K. Jang, S. Jeong. "Experimental investigation on convective heat transfer mechanism in a scroll compressor." International Journal of Refrigeration 29.5 (2006): 744-753, doi: $10.1016 /$ j.ijrefrig.2005.12.002

16. L. Guangbin, Z. Yuanyang, L. Liansheng, S. Pengcheng, "Simulation and experiment research on wide ranging working process of scroll expander driven by compressed air." Applied Thermal Engineering 30.14-15 (2010): 2073-2079, doi: 10.1016/j.applthermaleng.2010.05.015 